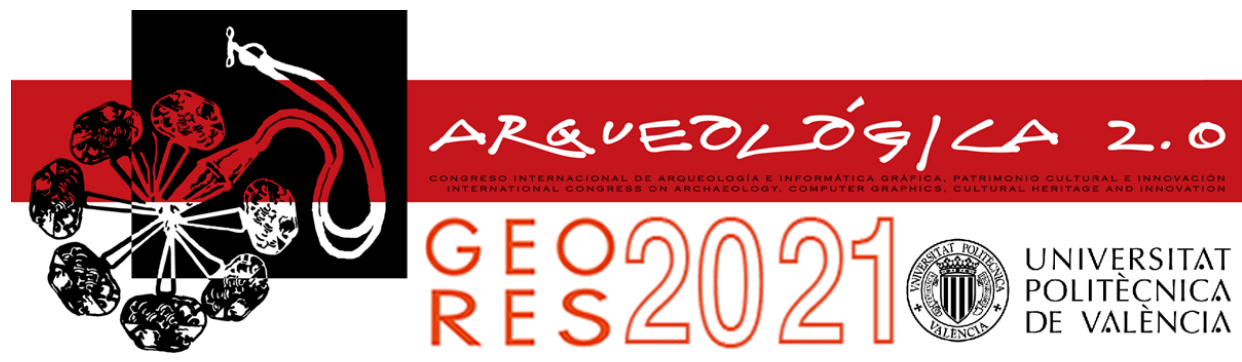

\title{
DETECTING AND MAPPING FLASH FLOODING WITH SYNTHETIC APERTURE RADAR (SAR) SATELLITE DATA: THE METAPONTO PLAIN CULTURAL LANDSCAPE CASE STUDY
}

\author{
Marzia Gabriele \\ Department of Architecture, Built Environment and Construction Engineering (ABC), Politecnico di Milano, Via Giuseppe Ponzio 31 , \\ 20133 Milano, Italy. marzia.gabriele@polimi.it
}

\begin{abstract}
:
Due to Climate change, unpredictable and uncertain weather conditions increase the likelihood of natural disasters, which correlates to major impacts on Cultural Landscapes and Heritage sites. Thanks to SAR sensors, continuous and rapid information can be collected with satellite data. When a sensor generates a directed beam of pulses, terrain returns highresolution radar-frequency reflected energy, enabling a first effective data implementation, helping to quickly localize where damage occurred during a flash-flood event. This could facilitate after-disaster response through rapid delivery and coordination of rescue operations. Synthetic Aperture Radar (SAR) data is capable of passing through clouds and weather phenomena and continuously monitor a flooding event by plotting its patterns for a cost-effective flood mapping. Free availability of SAR data through the European Space Agency's (ESA) Sentinel-1 SAR mission created a major opportunity for flood extent monitoring. The chosen case study is the area of the Metaponto Plain in Basilicata, southern Italy, which recently earned a candidacy as UNESCO site. In the effort of protecting cultural landscape and archaeological heritage, local authorities have to face multiple challenges coming from climate change and the impact of human activity. The object of this study is the flash-flooding event occurred on the $12^{\text {th }}$ of November 2019, which was reported to be an extreme hydrological event, causing important damages to the agricultural landscapes and cultural heritage sites. The Metaponto area exemplifies multiple pressures deriving from climate change and human activity, thus having to cohabit within an important cultural landscape and archeological heritage. The workflow here presented can be quickly implemented to extract information through simple and effortless algorithms, providing mid-regional scale event maps with a good resolution, and it is formally aimed at user-end Control Centres for putting in place rapid risk mitigation actions.
\end{abstract}

Keywords: climate change, hazard mapping, cultural landscapes, flash-flooding, cultural heritage, SAR

\section{Introduction}

Emergencies happen, and it is essential for government institutions to respond as soon as possible, estimate damage rapidly, and administer support payments in a short space of time (NEREUS, 2018). Timely and continuous information about flood dynamics are fundamental to ensure effective implementation of the relief and rescue operations (Lacava et al., 2019). The flood risk management cycle is comprehensive of different intricate phases (i.e. mitigation, preparedness, response, recovery), moreover, it is important to stress the crucial intake given by the flood monitoring and mapping activities. Flood mapping is the starting point and the solid base of the rest of the risk management process (Sanyal \& Lu, 2004; Ward et al., 2018). Mapping the flood during or after a flooding event helps to monitor water expansion and regression and to delineate what are the areas which, in different time threshold, have been invested by the hazard, and so where to concentrate further investments for monitoring flood hazards and land vulnerability overtime (Sanyal \& Lu, 2004; Franci, Mandanici, \& Bitelli, 2015). These products can be used for flood-prone area delineation in order to prevent future floods, providing crucial information to identify appropriate protection measures and strategies for risk mitigation and producing efficient response plans (Lacava et al., 2019; Dasgupta et al., 2018).

Nowadays, the availability of multiple satellite data can be used as an effective alternative to monitor the flood situation and extent in the particular area (Brivio, Colombo, Maggi, \& Tomasoni 2002; Rahman \& Thakur, 2018). Bad weather conditions during and after food events can represent a strong constraint to the utilization of optical remotely sensed data. For this reason, spaceborne radar systems, because of their exclusive cloud penetration capacity, offers a primary tool for realtime assessment of flooded areas, specifically synthetic aperture radar (SAR) data. The introduction of SAR sensors has shown great potential for flood mapping due to their independence from solar illumination and very low dependency on atmospheric conditions (Greifeneder, Wagner, Sabel, \& Naeimi, 2014; Uddin, Matin, \& Meyer, 2019) as in fact, due to the penetration capacity of synthetic aperture radar (SAR) data through clouds and hazy atmospheric circumstances like fog, smog, light rain, 
mist etc., it has the ability to the continuous observation of flood events for producing accurate, rapid and costeffective flood mapping (Rahman \& Thakur, 2018). SAR sensors are able to detect flooding because flat surfaces reflect (acts as a specular reflector) the signal away from the sensor, decreasing the amount of returned radiation (Gan, Zunic, Kuo, \& Strobl, 2012; Rahman \& Thakur, 2018). This causes relatively dark pixels in radar data for water areas which contrast with non-water areas (Rahman \& Thakur, 2018). The disadvantages of the use of radar sensors lie in the difficult classification of the acquired signal because of the influence of complex ground and system variables (Brivio, Colombo, Maggi, \& Tomasoni 2002). To improve this situation, multi-temporal techniques based on detection of changes between radar images acquired before and after the inundation event are usually recommended (Badji et al. 1994; Brivio, Colombo, Maggi, \& Tomasoni 2002; Wang, Koopmans, \& Pohl, 1995; Profeti \& Macintosh 1997; Rahman \& Thakur, 2018; Takeuchi, Konishi, Suga, \& Kishi, 1999). Today, spaceborne synthetic aperture radar (SAR) systems are the most preferred option for monitoring flood condition. Studies have demonstrated that SAR images are useful for determining flood extent during a disaster (Ajmar et al., 2017; Ohki et al., 2016; Uddin, Matin, \& Meyer, 2019; Voormansik, Praks, Antropov, Jagomägi, \& Zalite, 2013).

This research aimed at evaluating the flooded areas using Sentinel-1A and Sentinel-1B SAR data during an emergency flash-flood event. The specific objectives were as: (i) flood inundation mapping using multi-temporal Sentinel-1A and Sentinel-1B SAR images; (ii) map the flood-prone areas at risk in a territorial context of cultural heritage and cultural landscapes (iii) rapid flash-flood analysis using multi-date flood maps.

The Sentinel data are available as part of the Copernicus program. Formerly Global Monitoring for Environment and Security (GMES), it is nowadays a major space development program launched by the European Commission (EC) in partnership with the European Space Agency (ESA) in 2014. Its main purpose is to ensure Europe's sustainable development, enhance international competitiveness, security and realize real-time dynamic monitoring of the environment by coordinating, managing and integrating the observation data of existing and future European and non-European (third-party) satellites. Users of Copernicus services are policymakers and public authorities who need the information to develop environmental legislation and policies or to take critical decisions in the event of an emergency, such as a natural disaster or a humanitarian crisis but also for more sustainable everyday life (Guo, Fu, \& Liu, 2019).

\section{The study area}

Mediterranean Basin's lands are of a very long history of intensive use by man, apparently longer and more intensive than that of the other Mediterranean regions of the world. This feature confers unique adaptations to several components of the Basin's biodiversity, and some characteristic features to the structure and function of its ecosystems, especially with respect to their responses to human impact, including grazing, cultivation and fires (Naveh, 1990). Furthermore, meteorological studies suggest that the land-use changes in the Mediterranean Basin, accumulated over historical time and much accelerated during the last 30 years may have induced climatic change expressed in intensified winter rains and floods (Millán et al., 2005).

The Metaponto Plain is situated on the lonian coast of the Basilicata region, Southern Italy. The Site was founded by a Greek colony in the seventh century BC. Metaponto was a rich and flourishing centre of Magna Graecia and it was also the town where Pythagoras was born. Its archaeological area hosts the Palatine Tables, which are the remains of a hexastyle peripteral Greek temple of the sixth century BC, dedicated to the goddess Hera. Among the ruins of the ancient city, there are also the ruins of the Doric temple of Apollo Licio, with large monolithic columns and the ruins of a theatre dating back to the fourth century BC. The archaeological ruins of both Greek and Roman ancient civilizations located in this area made possible the proposal of the Metaponto plain as a UNESCO World Heritage Site. The Metaponto saw its historical evolution from the Bronze Age to the advent of the Romans, passing through the Greek colonization between the mouths of the Bradano and Basento rivers. The Greek colonization was mainly a conquest for the region's cultivated lands from which to extract agricultural and commercial profit. Greek immigration was sporadic at first, but then more and more massive. Between the seventh and third centuries $\mathrm{BC}$, the area was subjected to an intense and extensive agricultural organization, demonstrated by the dense subdivision still observable in the terraces, as well as in the numerous farms scattered throughout the territory. That was the moment where the parcellation, and the formal organization of land was formally set. The Greek agricultural grid is still seen nowadays as one of the fundamental valuable elements of the regional agricultural (and Cultural) landscape to be preserved together with all the other elements that add complexity to both traditional and contemporary landscapes, urban and rural, tangible and intangible, both archaeological remains and modern monuments (Council of Europe, 2000).

Referring to the concept of Landscape and Cultural Heritage preservation, it is strictly necessary to mention that the whole study area is an "area di notevole interesse pubblico" (area of remarkable Public Interest) protected and administrated by the State and the Region within the Art. 136 of the DIgs 42/2004 Codice dei Beni Culturali e del Paesaggio (Cultural Heritage and Landscape Law) (Figs. 1 and 2).

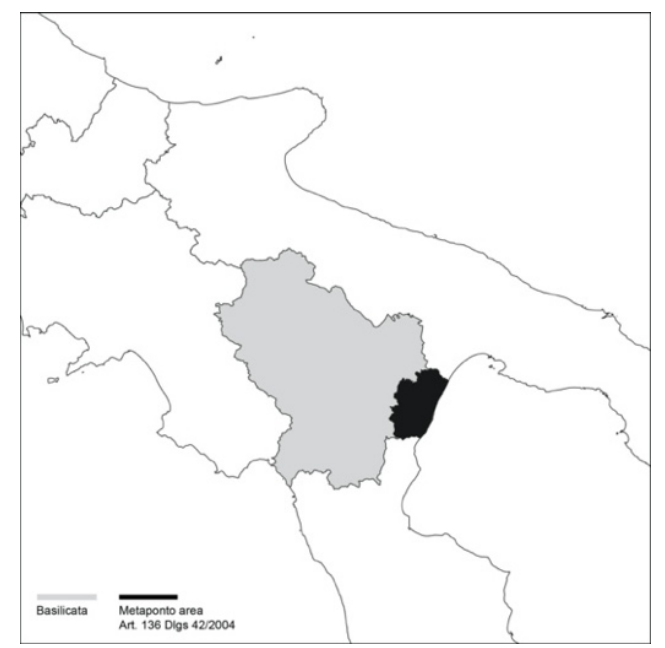

Figure 1: The localization of the Study Area in the context of Southern Italy and Basilicata region. 


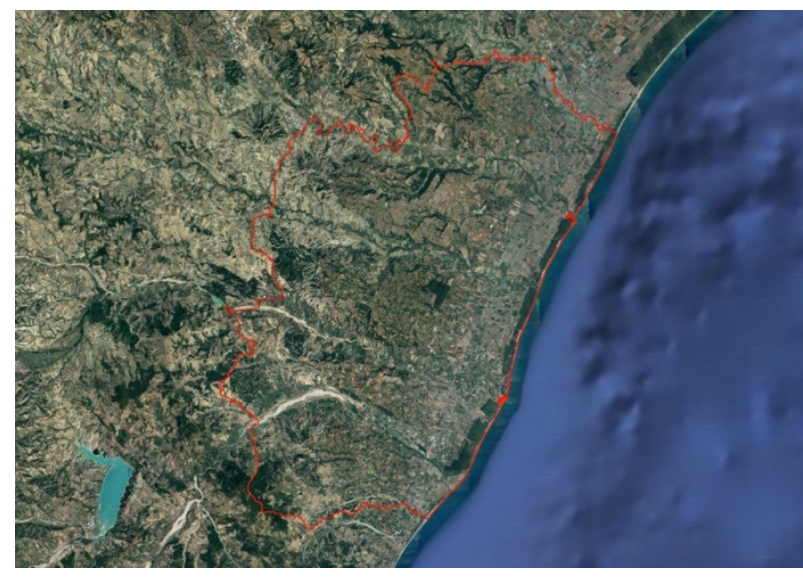

Figure 2: Metaponto Plain via Google Earth, 2020.

Apart from its Cultural value, the Plain itself is also a productive landscape, as it is one of the most important Italy's fruits and vegetable productions, with specialization in intensive cultivation of early species (strawberries, apricots, nectarine peaches), favoured by climatic and pedological conditions, characterized by a tendentially dry and mild climate in the periods of flowering of the fruit trees, and in those of ripening. This huge production was progressively achieved during the decades through the reclamation of the marsh areas and the channelling/filling of secondary channels. The Metaponto Plain area historically fell into the territories affected by the 1950 reform in Southern Italy, together with all the possible implications related to the pressure of its water bodies, as in fact the complete realization of the irrigation works triggered that specialization process towards an intense irrigated agriculture with a higher rate of profitability, thus triggering a higher hydrogeological risk. After this rapid overview, it is clear that the Ionian coast of the Basilicata region, southern Italy, is characterized by a remarkable archaeological heritage, valuable crops, and national and international tourism, contributing significantly to the regional economy. Unfortunately, from a geomorphological point of view, the Metaponto plain is particularly prone to suffer flooding (Bentivenga, Giano, \& Piccarreta, 2020; De Musso et al., 2018; Lacava et al., 2019). In the last two decades, the area has been affected by the heavy recurrence of flooding events, which caused significant damage to agriculture, tourist infrastructure, and archaeological heritage.

A huge number of river flooding happened because of persistent thunderstorms for extended periods. Among these, an important number of phenomena can be referred to flash floods, due to extreme rainfall occurred in few hours. In some cases, relatively shallow minor flooding due to the accumulation of excessive surface runoff has also been recorded (Bentivenga, Giano, \& Piccarreta, 2020).

A study carrying an accurate meteorological analysis on data from the National Civil Protection revealed that 23 extreme hydrological events occurred from 1921 to 1999 in the Ionian belt, whilst only 19 events have been recorded from 2000 to the present day (Bentivenga, Giano, \& Piccarreta, 2020). The recurrent flash floods caused huge economic damages in the studied area, such as the flood events of autumn 2013 that produced about 45 million euros of damages, involving farms damages in the Metapontino area for at least 27 million euros (Bentivenga, Giano, \& Piccarreta, 2020).

Furthermore, the last flood of November 2019, which is the one investigated for this study, caused damages up to 46 million euros in the area (Bentivenga, Giano, \& Piccarreta, 2020). Of course, the plain is prone to climaterelated flash flooding events, but it is still important to quote the human impact.

As aforementioned, during the past centuries, the Metaponto plain was an important part of a land reclamation project mainly consisting in the creation of an extensive channelling network, that aimed at providing assets for land cultivation, fast access to the beaches and archaeological heritage protection. Human impact related to the absence of channel cleaning has proved to be the most relevant factor that greatly amplified the effects of low-intensity rainfall events, thus triggering flooding events (Bentivenga, Giano, \& Piccarreta, 2020).

\section{Materials and method}

\subsection{Data used}

For flashfloods mapping and analysis, Sentinel-1A SAR and Sentinel-1B SAR data were used. SAR data was acquired for the date of $6^{\text {th }}$ and $12^{\text {th }}$ November 2019 (Sentinel-1A SAR $6^{\text {th }}$ November 2019 pre flashflood event and Sentinel-1B SAR 12 ${ }^{\text {th }}$ November 2019 after the event). The reference image was selected to be the 6 th of November, before the flash-flood event, because as previously mentioned multi-temporal techniques based on detection of changes between radar images acquired before and after the inundation event are usually recommended (Badji et al. 1994; Brivio, Colombo, Maggi, \& Tomasoni 2002; Wang, Koopmans, \& Pohl, 1995; Profeti \& Macintosh 1997; Rahman \& Thakur, 2018; Takeuchi, Konishi, Suga, \& Kishi, 1999). SENTINEL-1 carries a single C-band synthetic aperture radar instrument operating at a centre frequency of $5.405 \mathrm{GHz}$. It includes a right-looking active phased array antenna providing fast scanning in elevation and azimuth, data storage capacity of $1410 \mathrm{~Gb}$ and $520 \mathrm{Mbit} / \mathrm{s}$ X-band downlink capacity. The C-SAR instrument supports operation in dual polarisation $(\mathrm{HH}+\mathrm{HV}, \mathrm{VV}+\mathrm{VH})$ implemented through one transmit chain (switchable to $\mathrm{H}$ or $\mathrm{V}$ ) and two parallel receive chains for $\mathrm{H}$ and $\mathrm{V}$ polarisation. The presented study was entirely performed using VV polarized images. According to (Touzi, Deschamps, \& Rother, 2009; Twele, Cao, Plank, \& Martinis, 2016; Zhang, Li, Tian, Zhou, \& Tang, 2016; Zhang, Chen, Liang, Tian, \& Yang, 2020) it is much easier to detect flood water and avoid misclassifications with VV polarized images than $\mathrm{VH}$ polarized ones when the area is a low altitude vegetated plain with an agricultural vocation. There was no possibility to collect field data or to achieve a field validation immediately after the event, it is however reasonable to mention that this is an aspect that should be further implemented in the research for future investigations, carrying an in-situ validation of the methodology accuracy during the post-flooding events (e.g. (i) detailed after event field survey of the affected areas' perimeter by using the GPS system; (ii) UAV (Unmanned Aerial Vehicles) survey; (iii) in-situ flood marks field photographs, geographic coordinates of the damaged area and severity of the event information from 
local citizens (Singh, Dhote, Thakur, Chouksey, \& Aggarwal,2020).

\subsection{Methodology}

The methods used for this study are presented in (Fig. 3). Specifically, Sentinel-1 image classification for flood mapping, with initial pre-processing carried out to mitigate the SAR-typical speckle-noise signatures from the images. During the pre-processing step, the radiometric and geometric distortions were rectified due to the characteristics of the imaging system and imaging conditions and radiometric corrections (Radiometric Calibration, Radiometric Terrain correction) were performed to improve visualization and interpretation for flood mapping. The pre-processing steps, including data import, multilooking, radiometric calibration, speckle filtering, radiometric terrain correction, linear-tobackscattering coefficient decibel scaling (dB) transformation, were implemented using ESA's Sentinel Application Platform (SNAP). The open-access SNAP toolbox is capable of reading, pre-processing, and visualizing Sentinel-1 SAR images. The input is a calibrated Sentinel-1 GRD product $(10 \mathrm{~m}$ spatial resolution). After creating the subset of the area of interest (AOI) to investigate and after the Radiometric Calibration is applied, the image is firstly treated with a Radiometric Terrain Correction (RTC). RTC corrects geometric distortions that lead to geolocation errors.

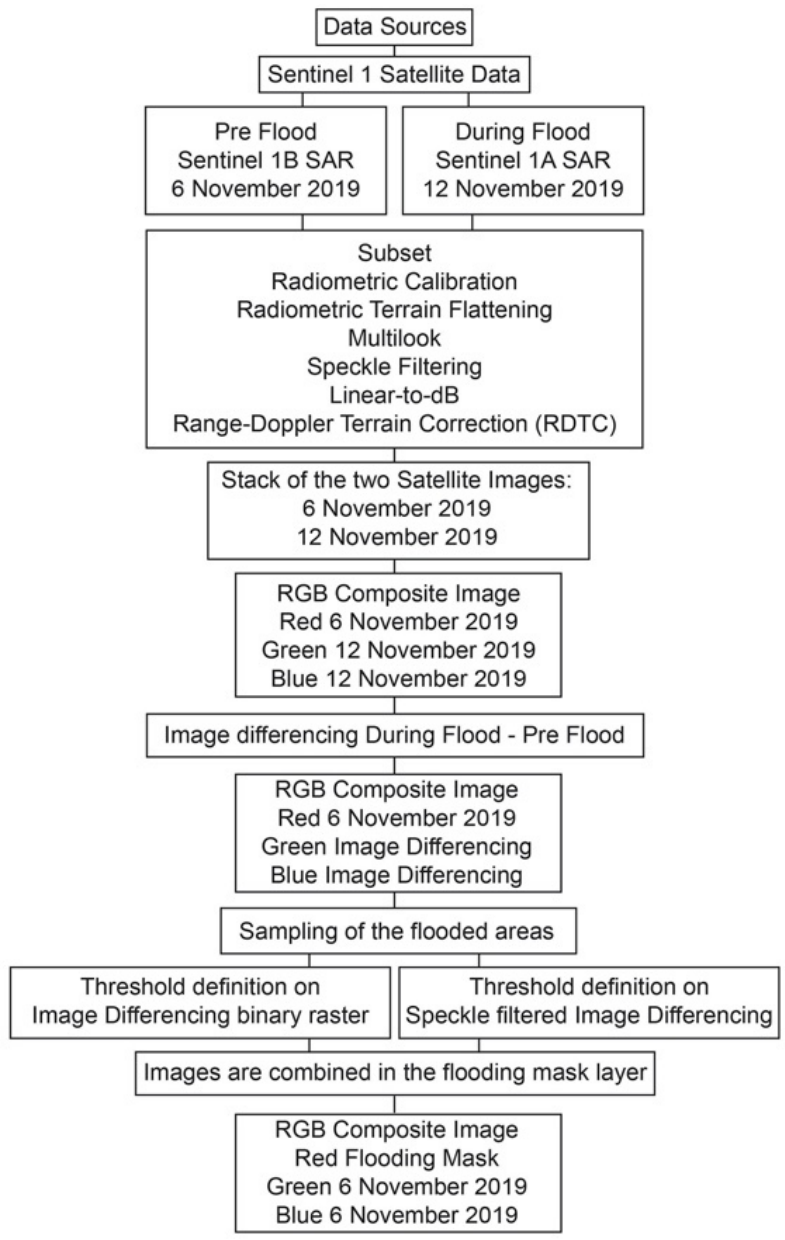

Figure 3: Workflow of the methodology presented in the study.
RTC (right) moves pixels to stretch the mountains and adjusts pixel values to subtract the effect of slopes on brightness, avoiding the distortions induced by sidelooking (rather than straight-down looking or nadir) that are compounded by rugged terrain. After RTC, the image is treated with a moderate single image multilook $(3 \times 3)$ in order to reduce speckle without degrading excessively the image resolution that passes from 10 to $30 \mathrm{~m}$. The fundamental characteristic recorded on a radar image is the backscattering coefficient, which may vary from surface to surface. The strength of the returned signal from the surface is influenced by the combined system and ground parameters, including the average surface roughness and soil dielectric properties. Horizontal smooth surfaces, such as water bodies, reflect nearly all incident radiation away from the sensor and the weak return signal is represented by dark tonality on radar images with the result that standing water areas are easily recognizable. This specular reflection can be decreased by bad weather conditions and/or the presence of vegetation, roughening the surface and making the detection of flooded areas more difficult (Brivio, Colombo, Maggi, \& Tomasoni 2002; Laugier et al. 1997). Moreover, SAR data are subject to speckle, a multiplicative random noise that considerably reduces the interpretability of the images and limits classification techniques, and SAR images have to be filtered in order to increase the signalto-noise ratio (Brivio, Colombo, Maggi, \& Tomasoni 2002). For these reasons, a Speckle Filtering was implemented in order to lower the backscattering noise and avoid a "salt and pepper" effect in the following passages. It is necessary to mention that: (i) the following passages were run parallelly on both the Speckle filtered and the no Speckle filtered images; (ii) the goal was to maintain the level of detail of the initial image with the no Speckle filtered image and to have the noises removed with the Speckle filtered image.

Then a decibel $(D b)$ conversion is applied to the image, which betters the comparison of two satellite images and permits to go from digital numbers to a physical quantity, which in this case is from Sigma Nought $\left(\sigma_{0}\right)$ backscatter to Sigma Nought Decibel ( $\left.\sigma_{0} D b\right)$ (Figs. 4 and 5); $\sigma_{0}$ is the backscatter returned to the antenna from a unit area on the ground. It is corrected for the local incidence angle and is thus in the realm of ground range. Sigma Nought $\left(\sigma_{0}\right)$ is the usual measure used to evaluate the reflectivity conditions of the surface, independent from geometric effects. This is often used in the scientific interpretation of SAR imagery. As the pixel values are absolutely calibrated, different SAR images in Sigma Nought $\left(\sigma_{0}\right)$ notation can easily be compared. When using Sigma Nought $\left(\sigma_{0}\right)$ in the SAR analysis workflow, it can be noticed that in the image-related histogram most of the pixels have a very low backscatter value, and there are a few pixels with a very high backscatter value. When converting the pixels from a linear scale to a nonlinear logarithmic scale, and so converting the images to decibel $\left(\sigma_{0} D b\right)$, the information related to the backscatter information performs a distribution histogram over the given colour range. This is due to the fact that in $\sigma_{0} D b$ the data is logarithmized (the conversion to $\mathrm{dB}$ transforms data into the logarithmic scale), distributing the SAR values evenly over the black/white colour range. This leads to a higher presence of grey pixels and less extreme values. It is not a compulsory prerequisite but helps visual interpretation and also statistical evaluation. Additionally, it increases the contrast, performing a much clearer 
distinction between black water and bright land pixels. The radiometric conversion from a linear scale to a $d B$ scale conducted is expressed using the following Eq. (1):

$\sigma_{0}(d B)=10 \cdot \log _{10} \sigma_{0}$

where

$$
\begin{aligned}
& \sigma_{0}(d B)=\text { backscattering image in } d B \\
& \sigma_{0}=\text { Sigma Nought image }
\end{aligned}
$$
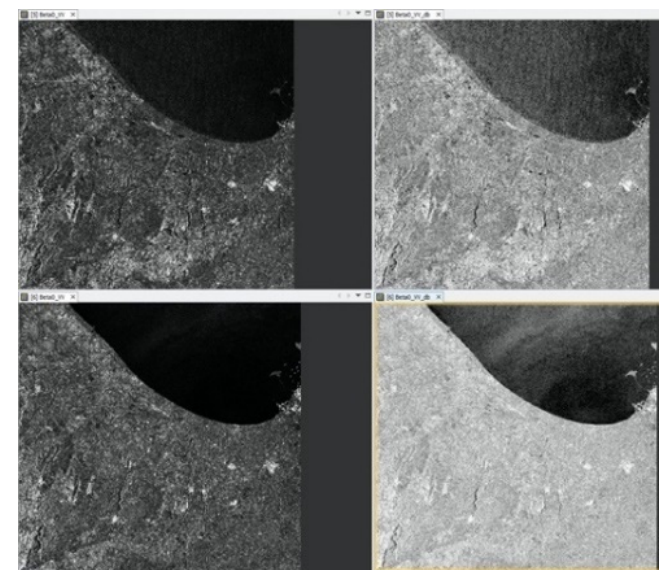

Figure 4: General From upper left, $12^{\text {th }}$ Nov. $\sigma_{0}$ without Speckle filtering; $12^{\text {th }}$ Nov. without Speckle filtering $\sigma_{0} d B ; 6^{\text {th }}$ Nov. $\sigma_{0}$ without Speckle filtering; $6^{\text {th }}$ Nov. without Speckle filtering $\sigma_{0} d B$.

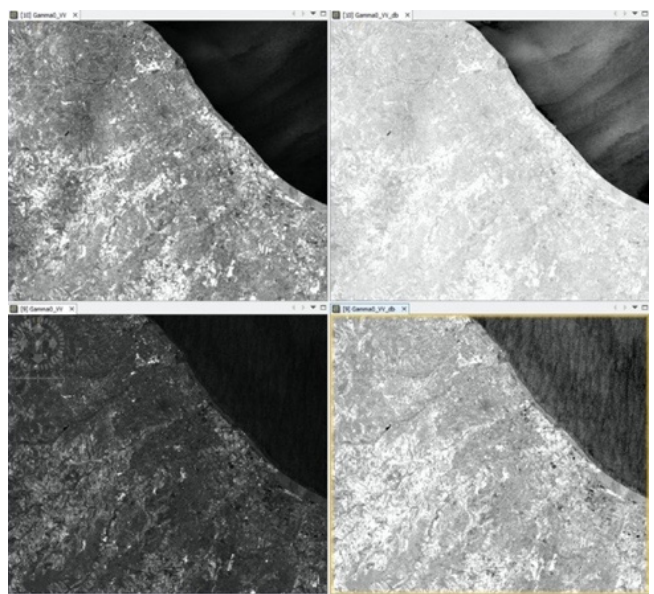

Figure 5: From upper left, $6^{\text {th }}$ Nov. $\sigma 0$ with Speckle filtering; $6^{\text {th }}$ Nov. with Speckle filtering $\sigma_{0} d B ; 12^{\text {th }}$ Nov. $\sigma_{0}$ with Speckle filtering; $12^{\text {th }}$ Nov. with Speckle filtering $\sigma o d B$.

The histogram shows two peaks, one peak corresponds to the pixels over land and the smaller peak corresponds to the pixels over water (Figs. 6-9).

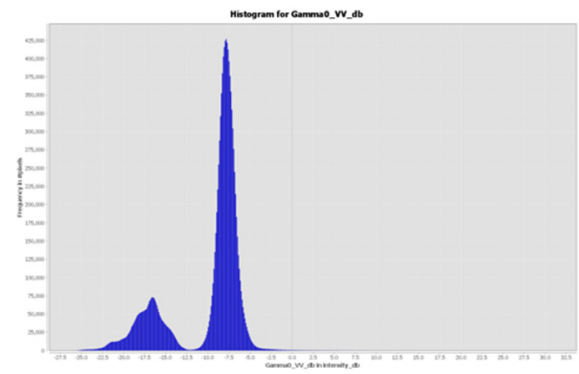

Figure 6: $6^{\text {th }}$ November $\mathrm{dB}$ scale Histogram with Speckle filtering.

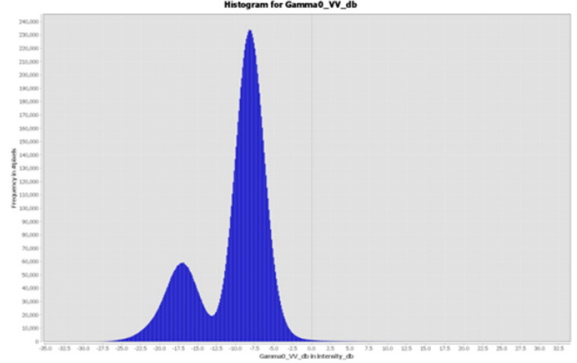

Figure 7: $6^{\text {th }}$ November $\mathrm{dB}$ scale Histogram without Speckle filtering.

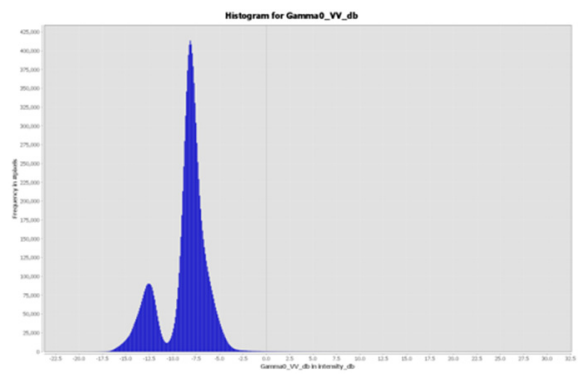

Figure 8: $12^{\text {th }}$ November $d B$ scale Histogram with Speckle filtering.

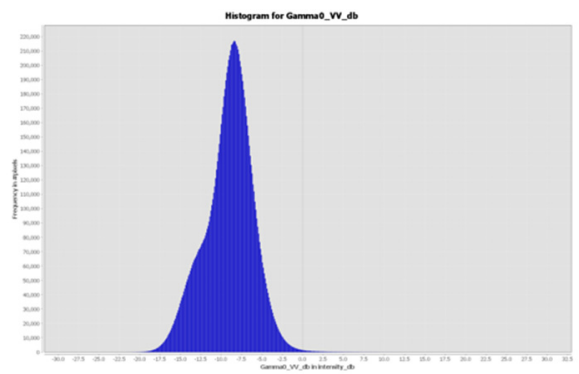

Figure 9: $12^{\text {th }}$ November $d B$ scale Histogram without Speckle filtering.

Finally, a terrain correction in order to project the pixels onto a map system and also correct the distortion over the areas of the terrain is made with a Range-Doppler terrain correction (RDTC). RDTC coordinate reference system (CRS) is World Geodetic System 1984 (Geodetic datum) with Geographic Lat/Long (WGS 84) for the projection.

The Range Doppler Terrain Correction (RDTC) operator implements the Range Doppler orthorectification method (Small \& Schubert, 2008) for geocoding SAR imagery from a single $2 \mathrm{D}$ of raster radar geometry. It uses available orbit state vector information in the metadata, the radar timing annotations, the slant to ground range conversion parameters together with the reference DEM data to derive the precise geolocation information (Bayanudin \& Jatmiko, 2016). Detail algorithm of this method can be found in (Small \& Schubert, 2008). The first step is the input/output parameter, using the imported SAR data as an input in orthorectification and choose the directory output for saving the orthorectified image. Input and output data are saved in one project file. The second step is defining the parameters and band amplitude VV which will be processed using SRTM 3 Sec as inputs to the DEM data, it will be automatically downloaded, both DEM and Image Resampling use bilinear interpolation method. Define a pixel spacing of $30 \mathrm{~m}$, thus this size will fit both to the orthorectified SAR data size in the GLS- 
2000 and the map projection that is used, UTM (Universal Transfer Mercator) and also the datum, WGS (World Geodetic System) 1984. After defining the parameters, then the process will be running automatically (Bayanudin \& Jatmiko, 2016).

Two couples of false-colour RGB band composites were performed in order to smoothly achieve a clear distinction of the areas invested by flash-flooding; it is important to mention that for carrying the whole workflow, the falsecolour RGB band composites were implemented for both speckle and not-speckle filtered images, this is the reason why they come in couples. The first couple of RGB composite allowed to achieve a first raw distinction between the flooded/not flooded areas; flooded areas were the ones having a high response on the red channel and derived from the combination of: (i) $12^{\text {th }}$ Nov. 2019 (green channel; blue channel), (ii) $6^{\text {th }}$ November 2019 (red channel). The second couple of RGB composite images was driven by the aim of having an image precisely detecting the inundated areas, to use as a reference for sampling the flooding wavelength and so define a threshold for it; this was possible to achieve using: (i) an image calculated from the differencing between the $12^{\text {th }}$ November 2019 flash flood event and the $6^{\text {th }}$ November 2019 reference image (green channel, blue channel), (ii) $6^{\text {th }}$ November 2019 (red channel).

To further express the abovementioned workflow, hereafter is explained the extended methodology. The first couple of RGB band composite was processed selecting the archive image for the red band $\left(6^{\text {th }}\right.$ November 2019) and the flooding crisis image for the green and the blue bands (12 ${ }^{\text {th }}$ November 2019). Radar response appears to have a high backscatter return in the archive image where flooded areas are not expected to be, and therefore, flooded areas appear to have a low backscatter return.

The flooded areas in the false colour RGB composite clearly have a high response in the red channel and a low response in the green and blue channels, whereas permanent water bodies have tones of grey as the backscatter (Fig. 10). After framing within the first rough RGB band composite what were the areas invested by the phenomenon (the ones having a high response in the red channel), the second phase of extracting the mapping of flooded areas using SAR data, involved (i) computing a band differencing to highlight the changes between the flooded and no-flooded areas; (ii) classify SAR images into water and non-water areas with a fixed threshold; (iii) create a flooding mask.

Firstly, for highlighting the changes in time between the flooded and not flooded areas, was computed a difference between the image acquired during the flash flood event and the reference image. In this way, it could be achieved a better evidence of the changes detected during pre and post event (Fig. 11).

Then, another false colour RBG composite was defined, deriving from the combination of (i) image differencing $\left(12^{\text {th }}\right.$ November 2019 flash flood event and the $6^{\text {th }}$ November 2019 reference image) in both the green channel and blue channel, (ii) $6^{\text {th }}$ November 2019 in the red channel. RGB helped to visually understand if the image differencing effectively achieved the goal of reaching a better precision in detecting changes. This is confirmed by the visible interdependencies between the darker zones (low reflection areas) of the image differencing, which are respectively present in the high response areas registered in the red channel of the RGB image (detecting inundated areas) (Fig.12).

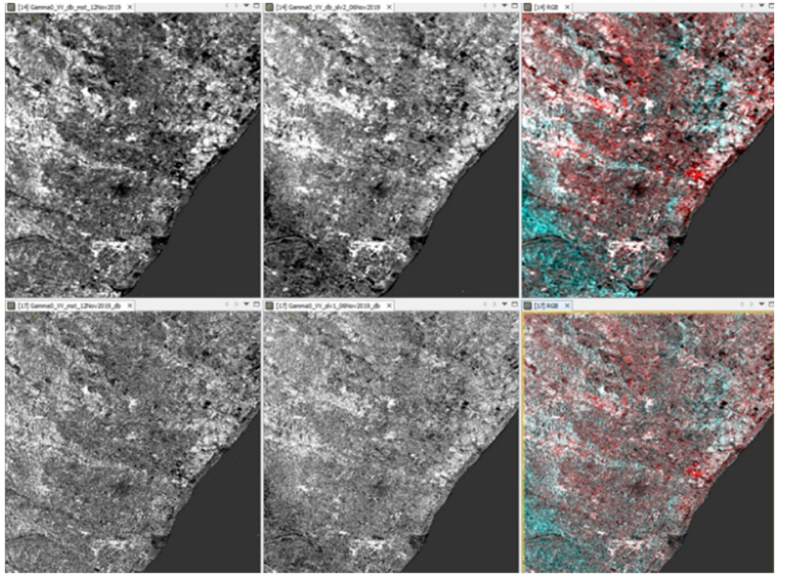

Figure 10: In the first row from the left: speckle filtered image of $12^{\text {th }}$ Nov. 2019, speckle filtered image of $6^{\text {th }}$ Nov. 2019, the RGB composite obtained; in the second row from the left: no speckle filtered image of $12^{\text {th }}$ Nov. 2019, no speckle filtered image of $6^{\text {th }}$ Nov. 2019, the obtained RGB composite.

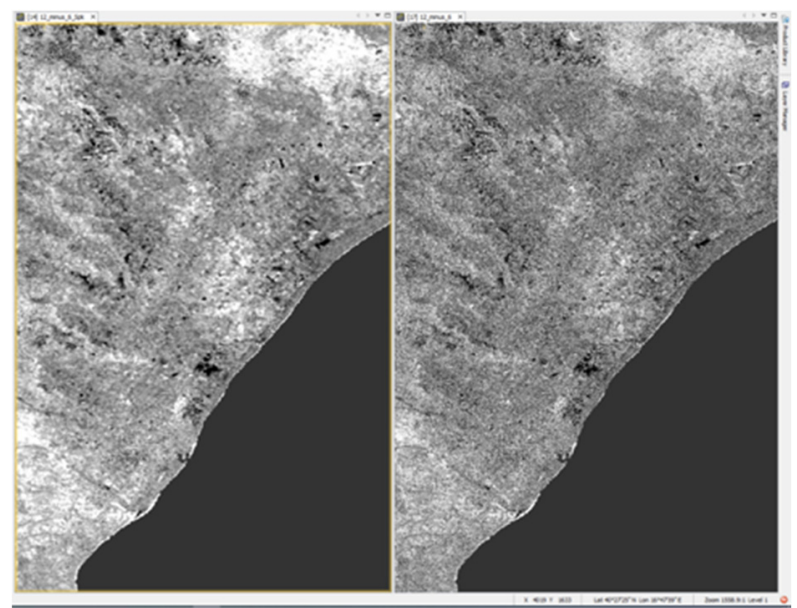

Figure 11: On the left, image differencing with speckle filter; on the right: image differencing without speckle filtering.

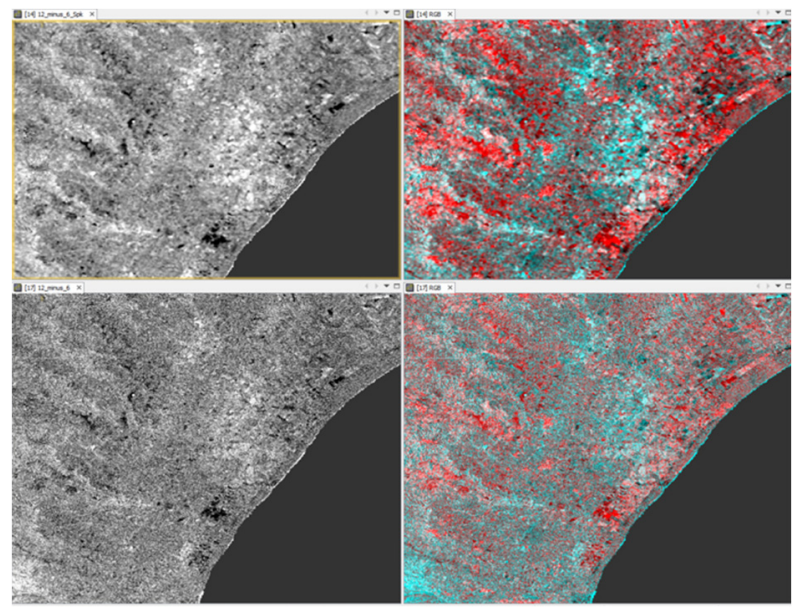

Figure 12: On the left, image differencing (up) with speckle filter (down) without speckle filtering; on the right RGB with image differencing on the Red channel (up) with speckle filter (down) without speckle filtering. 
The mapping of the inundated area was then extracted from the SAR images using the threshold method (Sheng, Gong, \& Xiao, 2001; Rahman \& Thakur, 2018). In SAR image inundated areas appear in a dark tone, which can be clearly delineated from the non-inundated areas due to the surface roughness of water and land (Rahman \& Thakur, 2018). The speckle filtered image differencing (SpkID) (calculated from the differencing between the $12^{\text {th }}$ November 2019 flash flood event and the $6^{\text {th }}$ November 2019 reference image) was the one taken as a sampling reference in order to investigate the flooded areas within the change detection framework. This due to the fact that the SpkID is the one having the lowest backscattering noise and so, allows a clearer interpretation of the phenomenon.

To determine an appropriate threshold value, manual sampling of representative flooded areas was carried out, based on the direct observation of the inundated zones, appearing as the areas with low reflection in the abovementioned speckle filtered image differencing (SpkID). In the threshold method, water areas are identified as the ones if SpkID $\leq T_{W}$, where SpkID is the speckle filtered image differencing applied to the SAR image and $T_{w}$ is the threshold value for water.

The threshold sampled values can be referred to as the histogram distribution of the image differencing pixel (Fig.13). From the location of the collected samples, it is clearly visible that the low reflection areas are concentrating in the negative region of the histogram, which is where the $T_{w}$ was set.

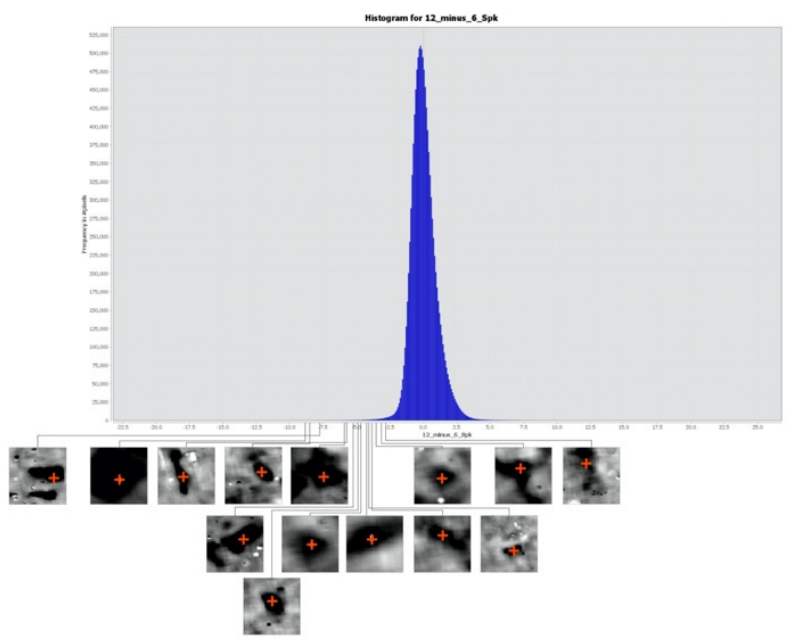

Figure 13: Extract of the sampled values referred to the histogram distribution of the image differencing pixels performed for the Speckle filtered image.

To create a flooding mask the two different layers were combined: (i) a binary map obtained by thresholding the image filtered with the speckle filter and (ii) the binary original threshold difference layer without the speckle filter (Fig. 14). The not speckled-filtered binary raster (iii) presents a high "salt and pepper" effect, but at the same time (iv) preserves the level of detail $(30 \times 30 \mathrm{~m})$; the speckle filtered image (v) does not present the "salt and pepper" effect but (vi) has a lower level of detail. After these considerations, it is reasonable to say that the final mask had to be computed as the one for which both conditions (iv) and (v) are satisfied. The final flood mask layer deriving from the combination of both speckle and not-speckle has the following advantages: (i) removes noise connected with the speckle effect and (ii) preserves the level of detail of the initial images (Fig. 15).

Finally, the last RGB composite was defined in order to see the flooded areas. RGB composite used the Flooding Mask on the red channel and the archive image $\left(6^{\text {th }}\right.$ November 2019 reference image) on the green and blue channels (Fig. 16). The area invested by flash-flooding on the day of 12 November 2019 covered $9,865 \mathrm{~km}^{2}$ of a total area of $819,814 \mathrm{~km}^{2}$

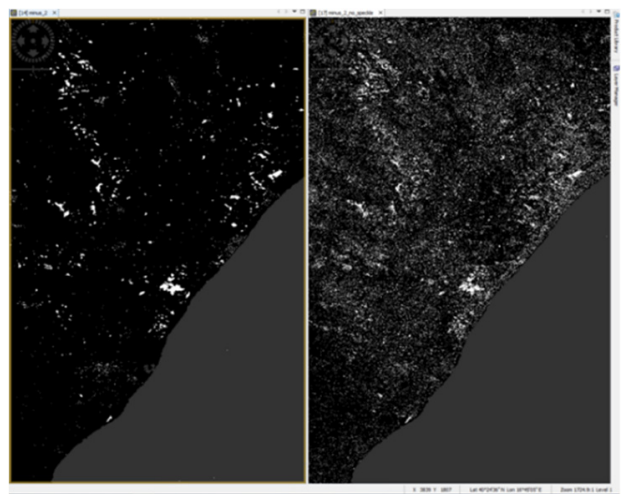

Figure 14: Threshold images, left: speckle filter; right: binary original threshold difference layer.

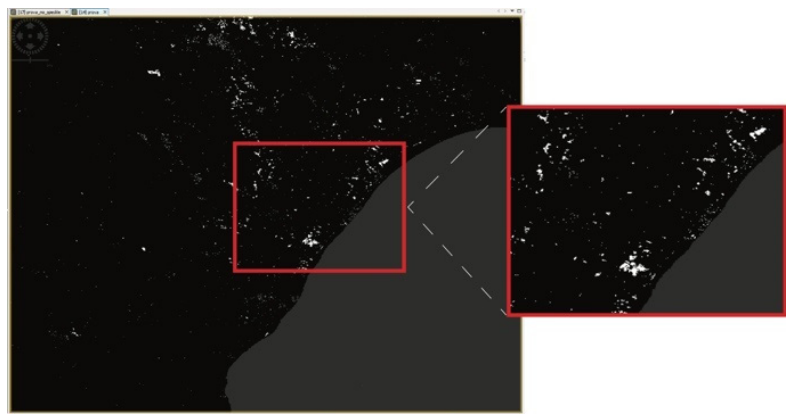

Figure 15: Flooding mask derived from the combination of the two threshold images.
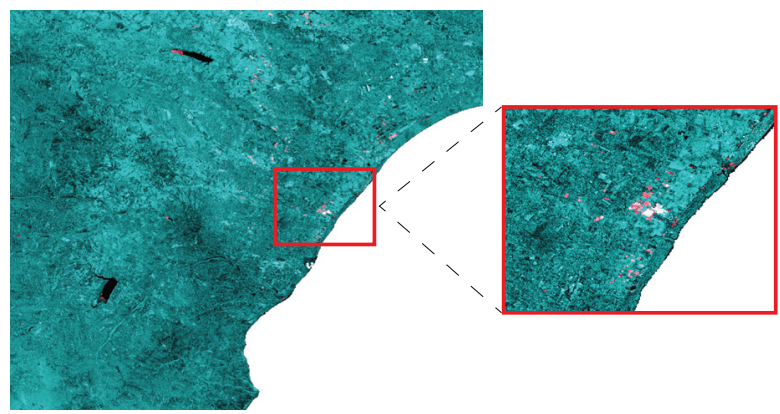

Figure 16: The RGB Composite deriving from using the Flooding mask on the red channel.

\section{Results and discussion}

To better understand and spatially locate the flooded areas in the Cultural Landscape and its Heritage, the mask layer was transferred to a QGIS environment and vectorized. The following layers extracted from both the MIBACT (The Ministry of Cultural Heritage and Activities) Open Database and Basilicata Open Data WebGIS were added to the final map, contextualizing the high Cultural value of the area (Fig.17): 
- Beni di Interesse Archeologico (Archeological Cultural assets) Art.10 Dlgs 42/2004. Cultural assets are immovable and movable things belonging to the State, to the regions, to other territorial public bodies, as well as to any other public body and institution and to private nonprofit legal persons, including civilly recognized ecclesiastical bodies, which are of artistic, historical, archaeological or ethnoanthropological interest.

- Beni Paesaggistici (Landscape Heritage) art. 142c Dlgs 42/2004. Rivers, streams, watercourses registered in the lists provided for by the consolidated text of the provisions of the law on water and electrical systems, approved by royal decree 11 December 1933, n. 1775, and the relative sides or feet of the embankments for a band of 150 meters each;

- Beni Paesaggistici (Landscape Heritage) art. 142c1 lettera a Dlgs 42/2004. These are the coastal territories included in a strip of the depth of 300 meters from the shoreline, also comprising the elevated lands on the sea;

- $\quad$ MIBACT (The Ministry of Cultural Heritage and Activities-Ministero per i Beni e le Attività culturali e per il Turismo), Open Data on Cultural Assets both Archeological and Architectonical.

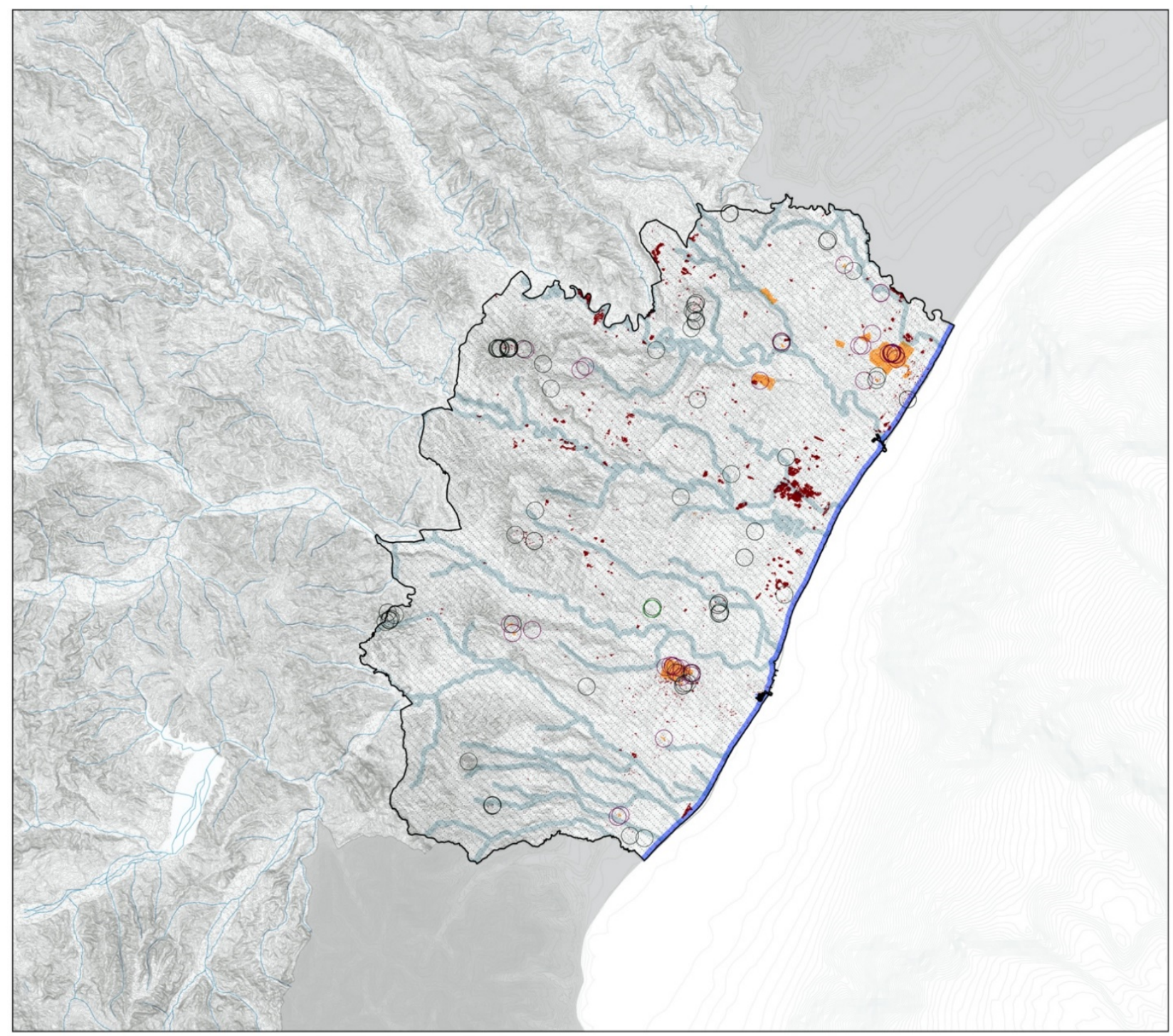

$\underline{0}$

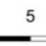

$\underline{10}$

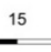

20

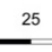

30 $40 \mathrm{~km}$

A
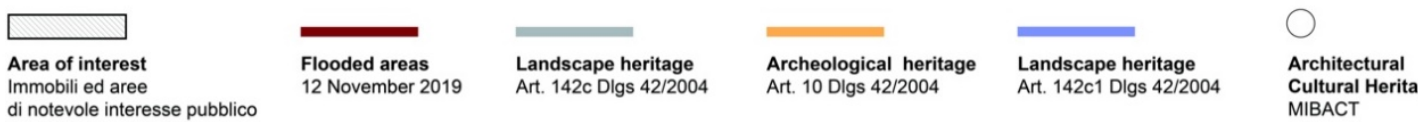

Architectural
Cultural Heritag MIBACT

Figure 17: The flooded areas and the Cultural, Archaeological, Architectonical and Landscape assets. 
As aforementioned in the introduction to the study area, we are dealing with a Heritage itself, which is the Metaponto Plain area, protected within the Dlgs 42/2004 (Codice dei Beni Culturali e del Paesaggio -Cultural Heritage and Landscape Code), in the Art. 136, as an "area of remarkable public interest".

"Acknowledging that the landscape is an important part of the quality of life for people everywhere: in urban areas and in the countryside, in degraded areas as well as in areas of high quality, in areas recognized as being of outstanding beauty as well as everyday areas (Council of Europe, 2000)". This is an extract of the European Landscape Convention, and perfectly fits in the organic idea of "protection" (the Italian tutela) as it shouldn't be something literally guided by the formal Landscape and Cultural assets, that rigidly design formal bounds of protection on the land.

As in fact, the Landscape as described in the European Landscape Convention is not only a list of aesthetic excellences where the recognition of historical-cultural value merges with the iconographic stasis of the "beautiful view" but is the result of a complex system of relationships that stratifies and evolves with the natural processes and the life of populations inhabiting it. Landscape and its assets are constantly evolving, as living things do.

The main aim of the protection from flash-flooding and extreme events, that progressively attacks the Heritage due to the unpredictable changing climate, should be constantly monitoring the whole, in order to act precisely and prompt when needed in time 0 and so avoid losses and irreplaceable damages.

The idea itself of the Metaponto Plain, which is formally invested by a protection law in its total area, it's the perfect example that if we don't take care of the whole, letting it undergo damages, we also lose part of the total significance of that one single element in it, even the one that maybe it is not considered "formally" remarkable, but still, is a fundamental part of the territorial entity and foremost of its Cultural identity.

\section{Conclusions}

Cultural Landscapes and Heritage sites are constantly facing risks deriving from unpredictable changes in the climate, resulting in a need for specific attention regardless of the formal existing legal constraints that yet protect them. The availability of Copernicus Sentinels Synthetic-Aperture Radar (SAR) data helps to achieve the mapping of disasters caused by flashfloods and extremely heavy rainfalls. Radar backscatter signal on the water is much different than the one on vegetated areas, allowing flood mapping with SAR radar to be almost undeniable. The idea behind the study is to demonstrate that monitoring Heritage at risk is achievable with a low-cost effective approach. The research presents a methodology based on the extraction of a food mask from SAR data by a series of simple algorithms that reach a $30 \times 30 \mathrm{mt}$ resolution with low "salt and pepper" noise disturbances. The presented analysis should have been further implemented with an after-event in-situ survey for validation in order to assess the overall accuracy. It is however important to stress the goal of rapidly individuating the flood-prone areas during a disaster, in order to frame the portions of land where to concentrate resources and further investigations in the subsequent phase of flooding management. The rapid response to flooding events in Heritage sites and Cultural Landscapes contexts is a key part of Heritage management, as it formally aims to avoid damages and thus, permanent losses.

\section{References}

Ajmar, A., Boccardo, P., Broglia, M., Kucera, J., Giulio-Tonolo, F., \& Wania, A. (2017). Response to flood events: The role of satellite-based emergency mapping and the experience of the Copernicus emergency management service. Flood Damage Surv. Assess. New Insights Res. Pract, 228, 213-228.

Badji, M. (1994). ERS-1 SAR imagery applied to rural basins hydrological studies: Flood inundation mapping and monitoring. European Space Agency-Publications-ESA SP, 365, 117-117.

Bayanudin, A. A., \& Jatmiko, R. H. (2016). Orthorectification of Sentinel-1 SAR (Synthetic Aperture Radar) Data in Some Parts of South-eastern Sulawesi Using Sentinel-1 Toolbox. In IOP Conference Series: Earth and Environmental Science (Vol. 47, No. 1, p. 012007). IOP Publishing. https://doi.org/10.1088/1755-1315/47/1/012007

Bentivenga, M., Giano, S. I., \& Piccarreta, M. (2020). Recent Increase of Flood Frequency in the lonian Belt of Basilicata Region, Southern Italy: Human or Climatic Changes?. Water, 12(7), 2062. https://doi.org/10.3390/w12072062

Brivio, P. A., Colombo, R., Maggi, M., \& Tomasoni, R. (2002). Integration of remote sensing data and GIS for accurate mapping of flooded areas. International Journal of Remote Sensing, 23(3), $429-441$. https://doi.org/10.1080/01431160010014729

COUNCIL, O. E. (2000). European landscape convention. US/ICOMOS Scientific Journal, 2, 88-92.

Dasgupta, A., Grimaldi, S., Ramsankaran, R. A. A. J., Pauwels, V. R., Walker, J. P., Chini, M., \& Matgen, P. (2018). Flood mapping using synthetic aperture radar sensors from local to global scales. Global Flood Hazard: Applications in Modeling, Mapping, and Forecasting, 55-77. https://doi.org/10.1002/9781119217886.ch4

De Musso, N. M., Capolongo, D., Refice, A., Lovergine, F. P., D’Addabbo, A., \& Pennetta, L. (2018). Spatial evolution of the December 2013 Metaponto plain (Basilicata, Italy) flood event using multi-source and high-resolution remotely sensed data. Journal of Maps, 14(2), 219-229. https://doi.org/10.1080/17445647.2018.1454349

Franci, F., Mandanici, E., \& Bitelli, G. (2015). Remote sensing analysis for flood risk management in urban sprawl contexts. Geomatics, Natural Hazards and Risk, 6(5-7), 583-599. https://doi.org/10.1080/19475705.2014.913695 
Gan, T. Y., Zunic, F., Kuo, C. C., \& Strobl, T. (2012). Flood mapping of Danube River at Romania using single and multidate ERS2-SAR images. International Journal of Applied Earth Observation and Geoinformation, $18,69-81$. https://doi.org/10.1016/j.jag.2012.01.012

Greifeneder, F., Wagner, W., Sabel, D., \& Naeimi, V. (2014). Suitability of SAR imagery for automatic flood mapping in the Lower Mekong Basin. International journal of remote sensing, 35(8), $2857-2874$. https://doi.org/10.1080/01431161.2014.890299

Guo, H., Fu, W., \& Liu, G. (2019). Scientific Satellite and Moon-Based Earth Observation for Global Change. Springer Singapore.

Lacava, T., Ciancia, E., Faruolo, M., Pergola, N., Satriano, V., \& Tramutoli, V. (2018). Analyzing the December 2013 Metaponto Plain (Southern Italy) Flood Event by Integrating Optical Sensors Satellite Data. Hydrology, 5(3), 43. https://doi.org/10.3390/hydrology5030043

Lacava, T., Ciancia, E., Faruolo, M., Pergola, N., Satriano, V., \& Tramutoli, V. (2019). On the potential of RST-FLOOD on visible infrared imaging radiometer suite data for flooded areas detection. Remote Sensing, 11(5), 598. https://doi.org/10.3390/rs11050598

Millán, M. M., Estrela, M. J., Sanz, M. J., Mantilla, E., Martín, M., Pastor, F., \& Versino, B. (2005). Climatic feedbacks and desertification: the Mediterranean model. Journal of Climate, 18(5), 684-701. https://doi.org/10.1175/JCLI-3283.1

Naveh, Z. (1990). Ancient man's impact on the Mediterranean landscape in Israel-ecological and evolutionary perspectives. Man's role in the shaping of the eastern Mediterranean landscape. Balkema, Rotterdam, 43-50.

NEREUS, European Space Agency and European Commission. (2018). "The Ever-Growing use of Copernicus across Europe's Regions: a selection of 99 user stories by local and regional authorities", 1-277.

Ohki, M.; Watanabe, M.; Natsuaki, R.; Motohka, T.; Nagai, H.; Tadono, T.; Suzuki, S.; Ishii, K.; Itoh, T.; \& Yamanokuchi, T. (2016). "Flood Area Detection Using ALOS-2 PALSAR-2 Data for the 2015Heavy Rainfall Disaster in the Kanto and Tohoku Area, Japan." Journal of The Remote Sensing Society of Japan 36, no. 4 (2016): 348-359. https://doi.org/10.11440/rssj.36.348

Profeti, G., \& Macintosh, H. (1997). Flood management through Landsat TM and ERS SAR data: a case study. Hydrological Processes, 11(10), 1397-1408. https://doi.org/10.1002/(SICl)10991085(199708)11:10<1397::AID-HYP530>3.0.CO;2-Y

Rahman, M. R., \& Thakur, P. K. (2018). Detecting, mapping and analysing of flood water propagation using synthetic aperture radar (SAR) satellite data and GIS: A case study from the Kendrapara District of Orissa State of India. The Egyptian Journal of Remote Sensing and Space Science, 21, S37-S41. https://doi.org/10.1016/j.ejrs.2017.10.002

Sanyal, J., \& Lu, X. X. (2004). Application of remote sensing in flood management with special reference to monsoon Asia: a review. Natural Hazards, 33(2), 283-301. https://doi.org/10.1023/B:NHAZ.0000037035.65105.95

Sheng, Y., Gong, P., \& Xiao, Q. (2001). Quantitative dynamic flood monitoring with NOAA AVHRR. International Journal of Remote Sensing, 22(9), 1709-1724. https://doi.org/10.1080/01431160118481

Singh, S., Dhote, P. R., Thakur, P. K., Chouksey, A., \& Aggarwal, S. P. (2021). Identification of flash-floods-prone river reaches in Beas river basin using GIS-based multi-criteria technique: validation using field and satellite observations. Natural Hazards, 105(3), 2431-2453. https://doi.org/10.1007/s11069-020-04406-w

Small, D., \& Schubert, A. (2008). Guide to ASAR geocoding. ESA-ESRIN Technical Note RSL-ASAR-GC-AD, 1, 36.

Takeuchi, S., Konishi, T., Suga, Y., \& Kishi, S. (1999). Comparative study for flood detection using JERS-1 SAR and Landsat TM data. In IEEE 1999 International Geoscience and Remote Sensing Symposium. IGARSS'99 (Cat. No. 99CH36293) (Vol. 2, pp. 873-875). IEEE. https://doi.org/10.1109/IGARSS.1999.774470.

Touzi, R., Deschamps, A., \& Rother, G. (2009). Phase of target scattering for wetland characterization using polarimetric C-band SAR. IEEE Transactions on Geoscience and Remote Sensing, 47(9), 3241-3261. https://doi.org/10.1109/TGRS.2009.2018626.

Twele, A., Cao, W., Plank, S., \& Martinis, S. (2016). Sentinel-1-based flood mapping: a fully automated processing chain. International Journal of Remote $\quad$ Sensing, 37(13), https://doi.org/10.1080/01431161.2016.1192304

Uddin, K., Matin, M. A., \& Meyer, F. J. (2019). Operational flood mapping using multi-temporal sentinel-1 SAR images: a case study from Bangladesh. Remote Sensing, 11(13), 1581. https://doi.org/10.3390/rs11131581

Voormansik, K., Praks, J., Antropov, O., Jagomägi, J., \& Zalite, K. (2013). Flood mapping with TerraSAR-X in forested regions in Estonia. IEEE Journal of Selected Topics in Applied Earth Observations and Remote Sensing, 7(2), 562577. https://doi.org/10.1109/JSTARS.2013.2283340.

Wang, F., Koopmans, B. N., \& Pohl, C. (1996). The 1995 Flood in the Netherlands monitored from Space-a multisensor approach. European Space Agency-Publications-ESA SP, 383, 469-472.

Ward, P. J., De Perez, E. C., Dottori, F., Jongman, B., Luo, T., Safaie, S., \& Uhlemann-Elmer, S. (2018). The need for 
mapping, modeling, and predicting flood hazard and risk at the global scale. Global flood hazard: Applications in modeling, mapping, and forecasting, 1-15. https://doi.org/10.1002/9781119217886.ch1

Zhang, M., Chen, F., Liang, D., Tian, B., \& Yang, A. (2020). Use of Sentinel-1 GRD SAR images to delineate flood extent in Pakistan. Sustainability, 12(14), 5784. https://doi.org/10.3390/su12145784

Zhang, M., Li, Z., Tian, B., Zhou, J., \& Tang, P. (2016). The backscattering characteristics of wetland vegetation and waterlevel changes detection using multi-mode SAR: A case study. International Journal of Applied Earth Observation and Geoinformation, 45, 1-13. https://doi.org/10.1016/j.jag.2015.10.001 